\title{
Aspectos subjetivos no processo comunicativo do design de espaços efêmeros: uma análise do espetáculo "Cão Sem Plumas"
}

The subjective aspects in the ephemeral design communication

process: analysis of the show "Dog Without Feathers"

\begin{abstract}
Alessandra Santos Lima da Cunha
Universidade do Estado de Minas Gerais

alesantosw@gmail.com
\end{abstract}

Simone Maria Brandão Marques de Abreu

Universidade do Estado de Minas Gerais

simonemarques1@gmail.com $\mathbf{x}$

Sebastiana Luiza Bragança Lana

Universidade do Estado de Minas Gerais

sebastiana.lana@gmail.com $\mathbf{x}$

PROJËTICA

\section{COMO CITAR ESTE ARTIGO:}

CUNHA, Alessandra Santos Lima da; ABREU, Simone Maria Brandão Marques de; LANA, Sebastiana Luiza Bragança. Aspectos subjetivos no processo comunicativo do design de espaços efêmeros: uma análise do espetáculo "Cão Sem Plumas". Projética, Londrina, v. 12, n. 2, p. 215-239, 2021.

DOI: 10.5433/2236-2207.2021v12n2p215

Submissão: 24-03-2021

Aceite: $24-03-2021$ 
Projética, Londrina, v. 12, n. 2, p. 215-239, agosto 2021

RESUMO: A pesquisa tem como objetivo ampliar as discussões acerca do design de espaços efêmeros e dos aspectos subjetivos no espaço. Para alcançar tal meta, foi realizado um estudo de caso da ambientação do espetáculo "Cão Sem Plumas" (2018), da Companhia de Dança Deborah Colker. Como resultado, percebe-se que esse espaço efêmero apresenta linguagens subjetivas capazes de despertar os aspectos sensoriais do humano e transmitir uma mensagem por meio de aspectos intangíveis.

Palavras-chave: Comunicação. Aspectos Subjetivos. Design de espaços efêmeros. Cenografia.

ABSTRACT: This research aims to broaden the discussions on the design of ephemeral spaces and the subjective aspects in such spaces. To achieve this goal, a case study was carried out with a focus on the setting of the show "Dog Without Feathers" (2018), from the Deborah Colker Dance Company. As a result, it is understood that this ephemeral space presents subjective manifestations that can awaken the human sensorial aspects and transmit a message through intangible aspects.

Keywords: Communication. Subjective aspects. Ephemeral design. Scenography.

\section{INTRODUÇÃO}

A sociedade atual, segundo o filósofo francês Gilles Lipovetsky (2005), apresentase em uma busca constante do hoje, do aqui e do agora, logo, rápida e pouco interessada nas relações com o outro e nas diferenças, as quais exigiriam do sujeito parada e reflexão. Há, de acordo com o referido autor, uma individualização ainda não vista até então pela história, seguida ainda por uma sensação de vazio, de uma vida alicerçada no pouco sentido das coisas, apoiando-se, assim, no eu e no efêmero. Bauman (2011) conceitua essa sociedade como líquida, cheia de velocidade e incertezas que, apesar das incertezas serem premissas do Ser, a 
contemporaneidade social, marcada por intensas inovações tecnológicas e pela globalização, vem com facilidade apagando e substituindo as coisas, que passam a estabelecer monopólios temporários.

Diante dessa realidade, percebe-se que o efêmero passa ser o melhor modo de representação do sujeito, por ser transitório ou temporário. O efêmero traz uma expressividade da vida, que deve ser entendida como o imperioso tempo vivido, ou seja, por ser passageira a vida, melhor vivê-la com intensidade no agora. Entretanto, há um aspecto negativo da efemeridade, a falta de aprofundamento em todas as formas de relacionamento, simplesmente pelo fato de ser momentâneo.

Percebe-se, então, que a comunicação ocorrida entre sujeitos e fatos precisa ser eficiente nesse momento, no qual o efêmero ganha estado da arte, para que a mensagem dessa comunicação possa atender plenamente ao indivíduo que é fruto da vivência acelerada. Por meio dessa configuração sociocultural da sociedade contemporânea, emerge a inquietação de qual seria a função social do design enquanto emissor dessa comunicação nos espaços efêmeros. Como os ambientes são projetados para melhor atingir esse sujeito social? E por qual meio é estabelecida a comunicação entre ambiente e usuário nos ambientes efêmeros?

Para que haja comunicação, segundo Romanini (2011), designer estudioso da semiótica, a mensagem deve ser significativa. Para ele, essa mensagem é um produto carregado de signos, que chega ao receptor de forma silenciosa. Logo, o ambiente, como produto de comunicação, passa ser mensagem sígnica, percebida pelos nossos sentidos, interpretada pelo cérebro e adequadamente absorvida pelo sujeito de forma subjetiva.

Em vista disso, é notável quão importante se torna um projeto de ambientes, no qual várias representações são estudadas para que a mensagem intangível $^{1}$ chegue ao sujeito de forma plena. No que diz respeito aos espaços

[1] O termo intangível, mencionado nesse artigo, diz daquilo que é intocável, volátil ou silencioso. 
Projética, Londrina, v. 12, n. 2, p. 215-239, agosto 2021

efêmeros, maior ainda essa relevância, pelo fato de que a comunicação precisa ser instantânea e eficiente, tendo em vista que este tipo de ambiente só existe por um curto período de tempo.

Então, diante do questionamento por qual meio é estabelecida a comunicação entre o usuário e os ambientes efêmeros, o presente artigo tem como objetivo geral contribuir para a ampliação das discussões sobre o tema de design de espaços efêmeros. Para atingir esse propósito, buscou-se alcançar os seguintes objetivos específicos: conceituar o design de espaços efêmeros; definir os aspectos subjetivos e indicar sua relação com o design; e, por fim, apontar os aspectos subjetivos presentes em design de espaços efêmeros por meio de um estudo de caso.

Assim sendo, foi escolhido como objeto de estudo o espetáculo Cão Sem Plumas, produzido pela coreógrafa Débora Colker. Esse espetáculo possui uma comunicação intangível significativa, a qual possibilitou identificar a mensagem subjetiva incidida no ambiente do efêmero, além de abordar uma importante parte da cultura brasileira, a denúncia social presente no poema Cão Sem Plumas de João Cabral de Melo Neto.

O processo metodológico utilizado foi pautado em uma vasta investigação bibliográfica que perpassou os seguintes assuntos: o design de espaços efêmeros, a cenografia, os ambientes cenográficos e os aspectos subjetivos. A partir desse embasamento, buscou-se aprofundar sobre o objeto de estudo escolhido através de uma coleta de dados tanto sobre o poema, quanto sobre o espetáculo, além de reunir imagens deste para a análise.

Por fim, esse artigo visa contribuir no que diz respeito à relevância da linguagem intangível nos ambientes efêmeros nos dias atuais, em especial no design, pelo fato que essa forma de comunicação tem se destacado por sua eficiência quando se trata de transmitir uma mensagem para uma sociedade que busca agilidade. 
Logo,acredita-se que essa linguagem é, e talvez será, a mais utilizada nos tempos vindouros. Por isso a necessidade de ser reconhecida, estudada e fundamentada para que os conteúdos transmitidos por ela sejam cada vez melhores.

\section{DESIGN DE ESPAÇOS EFÊMEROS}

O design de espaços efêmeros compreende o planejamento e a execução de projetos temporários. O termo efêmero tem origem na palavra grega ephémeros, que significa transitório, isto é, que apresenta um curto ciclo de vida e possui tempo previsto para começar e terminar. Assim, conforme Carnide (2012), a obra efêmera apresenta uma duração delimitada e prevê sua própria destruição.

No sentido etimológico da palavra, os espaços efêmeros surgiram no início das civilizações, no qual o ser humano precisava se deslocar constantemente em busca de alimentos e para fugir de ameaças. Assim, em virtude da necessidade de um lugar para abrigo a curto prazo, os povos nômades construíram as primeiras estruturas efêmeras, as tendas. Estas, por sua vez, tanto possibilitavam uma moradia a curto prazo quanto poderiam ser transportadas para outros locais de acordo com a urgência de deslocamento (MONASTERIO, 2006).

Os primeiros grandes eventos efêmeros surgiram por volta do século $\mathrm{XIX}$, com as Exposições Universais. Estes acontecimentos, que foram originados das transformações causadas pela Revolução Industrial, tinham como principal objetivo a disseminação do progresso tecnológico e industrial alcançado pelos países desenvolvidos do hemisfério norte. Porém, também estavam presentes exibições de obras de artes, produtos industriais, matérias primas e outros bens de consumo (BENEVOLO, 2004; MELIANDE, 2013).

Atualmente, em uma sociedade de consumo acelerado e que predomina a rápida aquisição e descarte de produtos, a fugacidade das coisas se tornou algo 
Projética, Londrina, v. 12, n. 2, p. 215-239, agosto 2021

comum. Nesse panorama, o design de espaços efêmeros ganhou destaque no mercado por atender à essência passageira e por impactar mais indivíduos com menos energia e matéria, apresentando baixo custo e rápida concretização. Logo, as principais características do design de espaços efêmeros são: leveza, portabilidade, facilidade de montagem, transitoriedade e economia de recursos (CARNIDE, 2012; NISHIKAWA, 2016).

Além desses fatores, Nishikawa (2016), afirma que outros aspectos são essenciais para a execução exitosa do espaço efêmero, como: narrativa, luz, tempo e som. A narrativa pode ser compreendida como a exibição - por meios visuais ou sonoros - de uma sequência de acontecimentos relacionados; a luz, por sua vez, refere-se aos efeitos luminotécnicos presentes no espetáculo, os quais permitem criar uma atmosfera para o ambiente; o tempo diz respeito a duração dos acontecimentos e a delimitação do ciclo de vida do evento; e, por fim, o som, o qual é constituído do movimento de vibrações de onda, que pode ser utilizado para narrar uma história ou criar uma atmosfera sonora no espaço.

Devido a temporalidade destes espaços, o evento efêmero possui uma única chance de transmitir uma mensagem para seu público alvo. Logo, para o êxito do design de espaços efêmeros, é necessário que a transmissão da mensagem para os espectadores ocorra de forma direta, com o maior impacto possível a ser realizado com os materiais disponíveis (FERNÁNDEZ-GALIANO, 2011).

Desse modo, percebe-se que o espaço - em especial o efêmero - é também composto por uma série de elementos subjetivos e intangíveis, que o diferencia dos demais tipos de ambientes que apresentam uma duração perene. Assim, ao analisar e projetar um ambiente, é essencial que seja levado em consideração tanto os aspectos físicos - organização de layout, cores, mobiliário, entre outros - quanto os componentes subjetivos, que revelam como o ser humano percebe o espaço e qual o significado gerado por trás dessa interpretação. O design de espaços efêmeros é, portanto, essencialmente composto por elementos materiais 
e, especialmente, por imateriais. Assim, como bem especificado por Abreu (2015) e por Nishikawa (2016) a imaterialidade pode ser percebida pelo ser humano por meios visuais, sonoros, pela luz e por todo o significado gerado dessa relação.

Quanto aos tipos de design de espaços efêmeros, pode-se definir algumas das principais categorias, tais como: exposições; feiras culturais; espetáculos teatrais/musicais; instalações artísticas; stands comerciais/culturais; vitrines; festas celebrativas; cerimônias culturais/religiosas e unidades pop-up. Para o desenvolvimento do presente artigo, tendo em vista o objeto de estudo a ser analisado, o foco será direcionado aos espetáculos teatrais/musicais, isto é, ao design de espaços efêmeros cenográficos.

\subsection{Cenografia: o ambiente cenográfico}

O termo cenografia pode ser compreendido como a técnica de projetar e representar paisagens, ambientes e lugares para cenas de apresentações teatrais. Partindo da etimologia da palavra, cenografia tem origem grega - skenographie- que é composto por skené (cena) e graphein (escrever e/ou desenhar) e era utilizada para se referir aos embelezamentos da cena. Segundo Mantovani (1989), a cenografia apresentase como uma composição em um espaço tridimensional, o lugar teatral.

A prática da cenografia está diretamente associada às encenações e ao teatro, tendo sua existência iniciada com o surgimento dos espetáculos teatrais na Grécia Antiga. É interessante notar que o teatro, assim como as demais artes, se diferencia de uma cultura para outra; logo, o teatro grego era tão diferente do teatro romano, quanto o da Antiguidade era distinto da Idade Média. Na Antiguidade, os cenários teatrais eram fixos e serviam como elementos de ornamentação para cena, enquanto na Idade Média a cenografia era dotada de um caráter místico e representativo de um lugar - como o céu e o inferno, por exemplo (MANTOVANI, 1989). 
Projética, Londrina, v. 12, n. 2, p. 215-239, agosto 2021

Desse modo, o conceito de cenografia tem se transformado ao longo do tempo e gerado discussões que vão além da proposta de planejamento de cenas para espetáculos teatrais. Em consonância com esse pensamento, Gonçalves (2004) afirma que ela passa então a ser entendida também como uma composição do espaço, no qual ocorrerá a exibição ou espetáculo, por meio da criação de um conjunto de aspectos concretos e subjetivos, chamada de atmosfera do ambiente.

Sobre a compreensão da cenografia como um arranjo que vai além dos aspectos tangíveis, é possível perceber nos últimos anos, uma maior aproximação da definição do termo com o campo da subjetividade. Por fim, pode-se dizer que a cenografia passa a ser um desenho de cena, um conjunto de imagens capazes de serem entendidas e captadas pelo público, comunicando conteúdos e significados (COHEN, 2007). Esses conceitos são importantes ao passo que conseguem transmitir uma ideia da cenografia como sensação, ou algo não tangível, denotando a fluidez desse lugar de cenas e a importância dos aspectos subjetivos nesse contexto.

Partindo do princípio que a cenografia transmite uma mensagem para o público de forma que o espectador possa emergir no contexto do espetáculo e viver uma experiência, por isso comunica, pode-se perceber que há uma significativa identificação, uma linguagem ou discurso entre a cenografia e o humano, os quais envolvem o sujeito. Todo esse envolvimento é conduzido de forma silenciosa, tanto pelo enredo, quanto pelo ambiente.

Um bom projeto de cenário é aquele que afeta a percepção do sujeito e faz com que ele se conecte com o fato. Para tanto, a fala silenciosa do ambiente cenográfico é aquela que melhor deve permitir o envolvimento do espectador com a cena. "Nossa subjetividade se expande nos espaços e estes passam a fazer parte de nós mesmos, tornando-se espaços apropriados, ou seja, "lugares" que nos abrigam, a nós e a nossos pertences" (CAVALCANTE; NÓBREGA, 2011, p. 212).

Os sentidos, desse modo, são os sensores que irão colaborar para a percepção do cenário proposto, expandir a relação entre a imagem e o sujeito 
e dar respostas significativas. A percepção é uma função cerebral que atribui significado aos estímulos recebidos pelos sentidos. Certamente, essa aferição será processada e interpretada pela mente humana na qual já possui conceitos, mitos e símbolos, construídos por meio das experiências e pela cultura. Entender sobre esses sensores, os quais o humano possui, é a melhor maneira de saber projetar cenografias, para que, por meio da mensagem intangível, seja possível captar o que seja de mais valoroso na comunicação.

\section{PERCEPÇÃO E SENTIDOS: OS ASPECTOS SUBJETIVOS}

De acordo com Okamoto (2002), a realidade é percebida por meio de conceitos, símbolos, mitos, dentre outros. Sendo assim, segundo ele, "não se tem na mente a realidade absoluta, mas somente aquilo que é perceptível por meio de fatos observáveis" (OKAMOTO, 2002, p. 22).

Abreu (2015) diz que "recebemos milhares de estímulos do meio, os quais são filtrados de acordo com o nosso interesse, interpretados conforme conceitos, símbolos e mitos, transformando-se em significados para o indivíduo ou para um grupo, no caso, a cultura" (ABREU, 2015, p. 27) e continua afirmando que “percepção é uma função cerebral que atribui significado aos estímulos recebidos pelos sentidos (ABREU, 2015, p. 28). Sendo assim, para que ocorra a percepção, os sentidos humanos são acionados, como sensores e, dessa forma, as informações captadas são transmitidas para o cérebro e decodificadas.

Hall (2005) nos traz que o equipamento sensorial do ser humano é dividido em duas categorias: remotos, os quais examinam objetos distantes - são eles os olhos, ouvidos e nariz - e, os imediatos, os quais examinam o mundo de perto, como o tato. Os olhos possuem um volume de captação de informações extraordinários, dentro de um raio de cem metros os olhos são bastantes eficientes. Os ouvidos conseguem captar sinais até uma distância de seis metros e meio. 
Projética, Londrina, v. 12, n. 2, p. 215-239, agosto 2021

De acordo com Okamoto (2002), a realidade é percebida por meio de conceitos, símbolos, mitos, dentre outros. Sendo assim, segundo ele, "não se tem na mente a realidade absoluta, mas somente quilo que é perceptível por meio de fatos observáveis" (OKAMOTO, 2002, p. 22). Abreu (2015) diz que "recebemos milhares de estímulos do meio, os quais são filtrados de acordo com o nosso interesse, interpretados conforme conceitos, símbolos e mitos, transformando-se em significados para o indivíduo ou para um grupo, no caso, a cultura" (ABREU, 2015, p. 27) e continua afirmando que "percepção é uma função cerebral que atribui significado aos estímulos recebidos pelos sentidos (ABREU, 2015, p. 28).

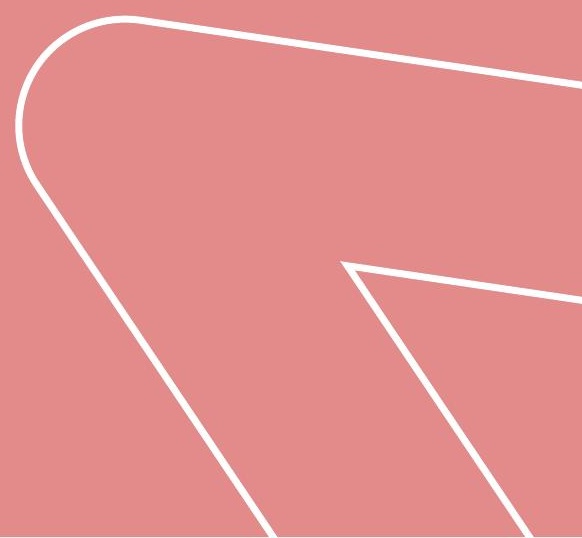


A percepção espacial também é considerada daquilo que é excluído. Há um descarte de percepção enquanto se presta muita atenção em um tipo de informação. Por respirarmos o tempo todo, o mundo olfativo é constante. As fibras nervosas do aroma percorrem um complexo caminho, algumas atingem o hipotálamo, centro que controla o apetite, o medo, a raiva e o prazer; outras atingem o hipocampo, que regula a memória e outras descem até o crânio, onde são reguladas as funções como a lembrança de respirar.

Essas ligações nervosas explicam porque os odores conseguem despertar respostas emocionais tão fortes e também seu vínculo com a memória. “O cheiro evoca recordações muito mais profundas que a visão e audição", (HALL, 2005, p. 56). "Ver é uma forma de tocar à distância, mas tocar fornece a verificação da realidade" (MONTAGU, 1988, p. 127).

"As experiências visuais e táteis do espaço estão tão entrelaçadas que não podem ser separadas" (HALL, 2005, p. 74). Por ser um órgão presente em todo o corpo, passa a ser o invólucro, delimitando território externo e interno. Desenvolvido desde a infância pelo estímulo do toque entre mãe e filho, pelo aleitamento materno, por exemplo, é um órgão que busca o acolhimento, o aconchego, a defesa física e emocional.

Além dessas percepções, outras traduções podem ser realizadas, unindo uma percepção com a outra e a sensação de seus significados. Quando se faz o uso da visão para perceber uma textura rugosa, por exemplo, mas não é possível tocála, tem-se a sensação de maciez, mesmo não se aproximando do objeto.

O subjetivo passa ser, então, a interpretação única que se tem diante das percepções captadas pelos sentidos. No momento em que os sensores são acionados, há um mundo de interpretações a serem realizadas no cérebro; são mensagens transmitidas, as quais serão compreendidas de forma rápida, silenciosa e única, por vezes, igualitárias entre os indivíduos, quando percebidas pelo olhar da cultura. 
Projética, Londrina, v. 12, n. 2, p. 215-239, agosto 2021

Por meio da percepção e dos sentidos uma mensagem pode ser interpretada. Uma quantidade de informações pode ser transmitida e captada de forma sígnica, logo, intangível e de leitura subjetiva. Entretanto, para que o design possa cumprir sua função, essa mensagem deve ser projetada e emitida de tal forma pelo designer, ao ponto de ser captada pelo sujeito e capaz de transformálo. Esse é o processo comunicativo do design de espaços efêmeros, o qual pode ser observado no estudo de caso a seguir.

\section{RESULTADOS}

Para alcançar os objetivos da pesquisa, desenvolveu-se uma metodologia de análise visual fundamentada no embasamento teórico realizado nos tópicos anteriores, bem como no poema "O Cão Sem Plumas" (1950), do poeta brasileiro João Cabral de Melo Neto.

A partir disso, buscou-se fazer a associação entre os trechos do poema e a composição da ambientação cenográfica do espetáculo desenvolvido pela Deborah Colker, mostrando como os elementos presentes na cena estavam relacionados com ideias que decorriam das questões materiais e que buscavam transmitir a crítica social por trás do poema. É válido ressaltar que, como a presente pesquisa ocorreu a nível teórico, não houve investigação prática com os espectadores do espetáculo, logo a análise decorre em torno dos possíveis efeitos da linguagem sob os espectadores, bem como identificar quais emoções e sentimentos podem ter sido despertados pela apresentação.

\subsection{Cão Sem Plumas: o espetáculo}

O espetáculo Cão Sem Plumas (Figura 1) foi produzido pela coreógrafa carioca Deborah Colker, com inspiração no poema de mesmo título de João Cabral de Melo 
Neto (1920-1999). A obra do poeta brasileiro foi inicialmente publicada na década de 1950 e relata um percurso de dor e sofrimento ao longo do rio Capibaribe, que corta grande parte do estado de Pernambuco. A ideia para o poema surgiu após Melo, que vivia em Barcelona, ler em um jornal que a expectativa de vida no Recife era menor que na Índia. A partir dessa notícia chocante, João Cabral buscou retratar no texto a pobreza da população ribeirinha do rio, o sofrimento de quem vive à beira do mangue e o descaso da elite para com esse povo.

Figura 1 - Espetáculo Cão Sem Plumas (2017)

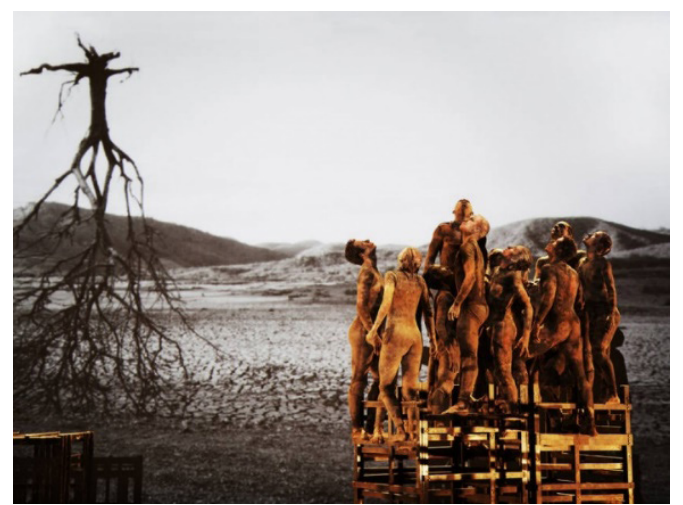

Fonte: BRASIL, 2017.

Com base no poema de Melo, Deborah Colker criou o primeiro espetáculo da sua companhia de dança com temática explicitamente brasileira. A apresentação de estreia ocorreu em 3 de junho de 2018, no Teatro Guararapes, em Recife, como forma de homenagear a cultura local do povo retratado no espetáculo. O evento contou com o patrocínio da Petrobrás, que tem sido parceira da Cia Deborah Colker desde 1995.

Sobre o Cão sem plumas, Colker alega que "o espetáculo é sobre coisas inconcebíveis, que não deveriam ser permitidas. É contra a ignorância humana. Destruir a natureza, as crianças, o que é cheio de vida". A partir da dança, a coreógrafa busca transmitir os sentimentos de angústia, sofrimento e desprezo retratado no poema de João Cabral. Além disso, nessa obra, Colker realizou uma notável interação entre espetáculo gravado e espetáculo vivo. 
Projética, Londrina, v. 12, n. 2, p. 215-239, agosto 2021

As cenas, que são reproduzidas em um grande telão utilizado como plano de fundo do espetáculo, foram realizadas por Colker e pelo diretor pernambucano de longas-metragens, Cláudio Assis. As imagens expostas no telão foram gravadas com 13 bailarinos na área compreendida entre o sertão e o agreste pernambucano até a zona urbana de Recife, com o intuito de retratar a cultura da região, expondo as características naturais do local. As cenas, que dialogam com produções musicais dos pernambucanos Jorge Dü Peixe e Lirinha - além da colaboração do carioca Berna Ceppas -, comunicam-se tanto com as coreografias executadas pelos bailarinos em palco, quanto com a cenografia do espaço.

Sobre a composição do figurino dos bailarinos, Colker explica que estes se cobrem de lama, em alusão às paisagens e manguezais descritos no poema de João Cabral de Melo Neto, e executam passos que fazem referência aos caranguejos, os quais são animais típicos do referido bioma. A construção do personagem evocado pelos bailarinos, o bicho-homem, foi baseada tanto nas manifestações culturais pernambucanas - como o maracatu e coco - quanto no jogo de ritmos proporcionados pelo samba, jongo e outras danças populares.

\subsection{Os aspectos subjetivos no design de espaços efêmeros}

O espetáculo Cão Sem Plumas (2018) é classificado como um design de espaços efêmeros por ser um espaço - teatral e cenográfico - que foi planejado para acontecer em um período específico do tempo, ou seja, para ter uma duração transitória. Neste ambiente cenográfico é possível identificar um conjunto de elementos que são responsáveis por comunicar uma mensagem ao público, tais como: a luz; a narrativa visual; o acessório da cena ${ }^{2}$; o figurino e o som. Este último, todavia, não será aqui analisado pela ausência de materiais que possibilitem a análise do mesmo no espetáculo, tendo em vista que seria necessária uma gravação da narrativa auditiva e sua respectiva associação com a sequência de cenas da apresentação.

O telão exposto no fundo do palco será aqui considerado como parte da narrativa visual, pois ele busca criar um plano de fundo, por meio de um filme gravado por Colker com os bailarinos no mangue do Capibaribe, para a construção 
do cenário do poema de João Cabral de Melo Neto, que é narrado verbalmente ao longo do espetáculo.

Com base no tópico citado sobre os aspectos subjetivos, buscou-se definir quais parâmetros imateriais seriam passíveis de análise por meio das imagens, tendo em vista que o maior número de registro desse espaço temporário se deu por fotografias. Os atributos subjetivos do espaço, apoiados nos sentidos humanos, transmitem uma mensagem visual ao espectador, que irá gerar interpretações com base no contexto pessoal de vivências socioculturais.

É válido ressaltar que os aspectos subjetivos do espaço também estão presentes em características materiais, como por exemplo a sensação e o sentimento despertado pela textura dos figurinos dos bailarinos. Estes vestuários podem ser identificados em dois tipos distintos, os quais aqui serão referidos como figurino A (à esquerda da figura 2) e figurino B (à direita da figura 2).

Figura 2 - Figurino A e Figurino B do espetáculo Cão Sem Plumas (2017)

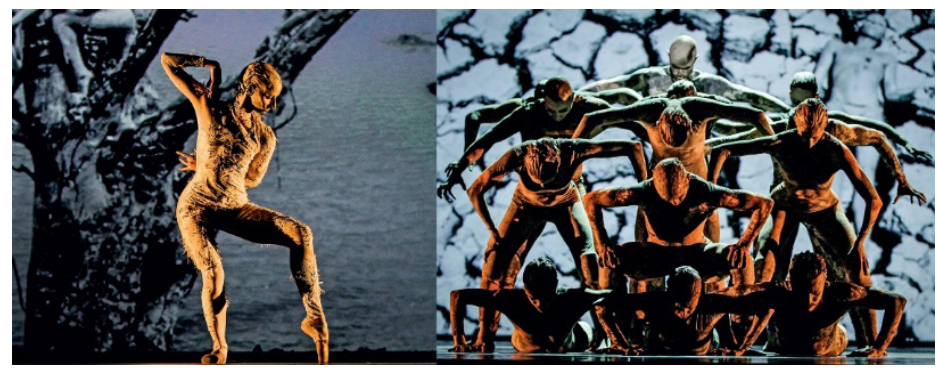

Fonte: Magalhães (2017)

Segundo a autora Flávia Suassuna, o cão desplumado é uma metáfora utilizada por Cabral para se referir ao rio Capibaribe, mencionando a relação intensa do rio com aqueles que vivem a sua margem (o homem-caranguejo) e que, também, são cães sem plumas. Desse modo, é possível perceber que o figurino A, que faz referência a uma pele que teve suas plumas arrancadas, tendem a despertar aspectos intangíveis de dor, sofrimento e abandono, estando essa sensação ligadas aos trechos do poema de Cabral, como em: "Como o rio / aqueles homens / são

[2] Objetos que fazem parte da construção espacial da cenografia, com os quais os dançarinos interagem. 
como cães sem plumas / um cão sem plumas / é mais / que um cão saqueado; / é mais / que um cão assassinado". Despertar sentimentos significa que, por meio do sensor visão, a imagem foi captada, interpretada pelo cérebro, codificada e devolvida em forma expressiva de dor, sofrimento e abandono.

Observa-se, também, que a textura ao ser captada pela visão, e percebida pelo tato, pode expressar amplo sentimento, uma mistura de conexões, interpretações, que podem avançar por todo o corpo do espectador, tudo isso de forma profundamente silenciosa. Ainda com base nesse contexto, o figurino $B$ busca retratar o bicho-homem, ou o próprio homem-caranguejo, por meio de um aspecto de pele recoberta por lama, representando a pobreza daqueles que vivem próximos ao mangue e dependem do rio.

A respeito dos acessórios de cena, que são objetos introduzidos no palco, com os quais os bailarinos interagem, envolvem dois tipos de artefato: as fitas (Figura 3) e as jaulas-palafitas (figura 4).

Figura 3 - Fitas no espetáculo Cão Sem Plumas (2017)

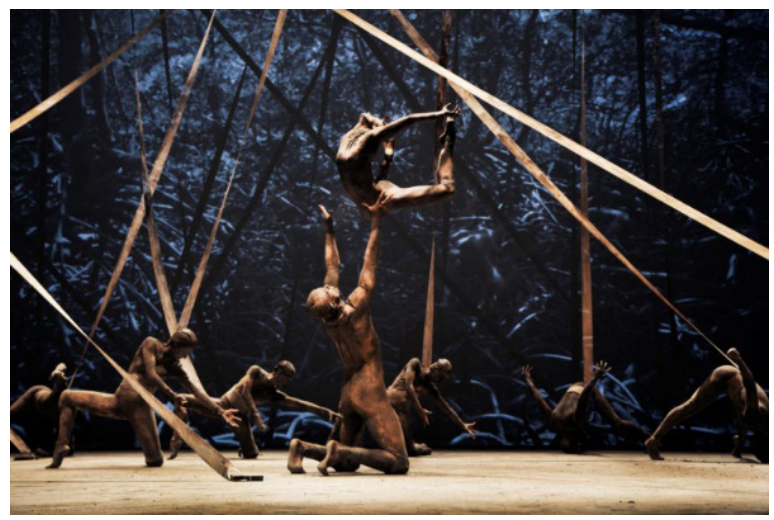

Fonte: Viegas (2017)

As fitas são introduzidas na cena como objetos com os quais os bailarinos interagem e sobrepõem o plano de fundo do palco, o telão, que pode conduzir o espectador a uma narrativa visual no cenário de referência - os ásperos galhos do manguezal. Ao se apropriarem das fitas no palco, os bailarinos conduzem as fitas em ritmos ordenados que levam ao cruzamento das mesmas, apresentando uma sobreposição de linhas em várias direções que fazem referência ao aspecto visual encontrado na vegetação do mangue, a qual pode ser vista na Figura 4. 
São linhas, galhos e entrelaçamentos que têm o intuito de confundir a mente do espectador e o fazer refletir: mangue, lama, homem, rio, um mundo de indagações emergem e podem levar o espectador a uma conexão única, fazendo brotar da pele para dentro, de dentro para a pele: quem sou? Que é esse mundo que não tem plumas, que tem osso, que tem lama, lodo... Entretanto, tem alma, por isso tem fluxo, tem existência... Essa cena pode ser percebida no seguinte trecho de Cabral: "na paisagem do rio, difícil é saber onde começa o rio; onde a lama começa do rio; onde a terra começa da lama; onde o homem, onde a pele, começa da lama; onde começa o homem, naquele homem".

Figura 4 - Registro da vegetação no Rio Capibaribe

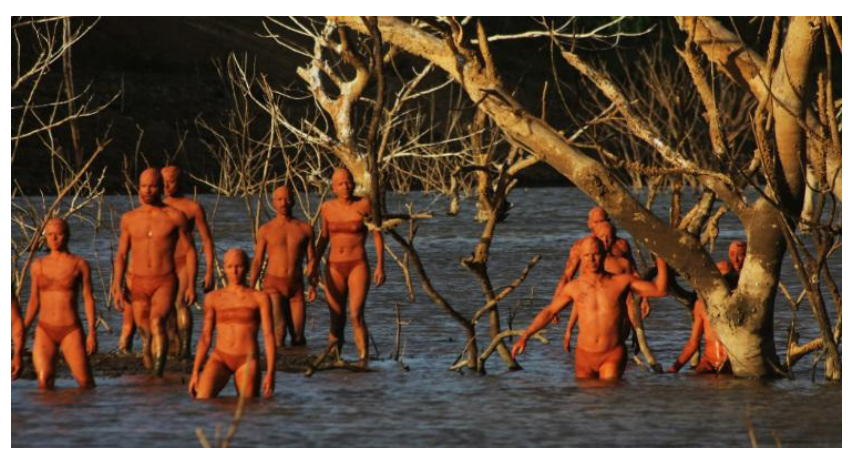

Fonte: Romero (2017)

As jaulas-palafita (figura 5), feitas de madeira, são estruturas utilizadas em palco como signo do lugar onde moram os ribeirinhos, ou seja, as casas de palafitas às margens do rio que compõem os aglomerados no Recife, e de prisão, por essas pessoas estarem confinadas em uma realidade retratada por Cabral como sendo de miséria, seca e fome.

Figura 5 - Jaula-palafita no espetáculo Cão Sem Plumas (2017).

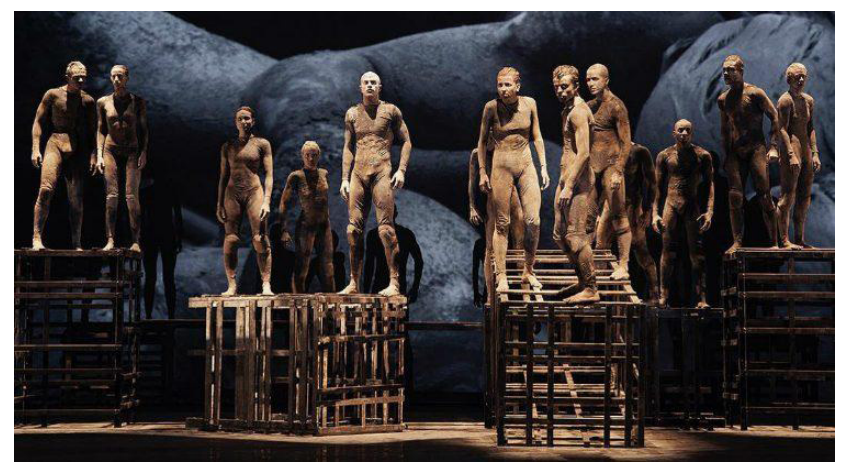

Fonte: Romero (2017) 
Esse pensamento pode ser encontrado nos seguintes trechos do poema: "Entre a paisagem / (fluía) / de homens plantados na lama; / de casas de lama / plantadas em ilhas / coaguladas na lama; / paisagem de anfíbios / de lama e lama". Percebe-se assim, a ausência de uma delimitação entre o homem e o rio, demonstrando que eles estavam interligados e que a aridez que afetava o rio refletia no ser humano que ali habitava.

Já a luz de cena é uma magia que incide sobre os objetos e propicia uma intensa percepção de formas, cores, texturas, espaço e movimento. Na Figura 6, observam-se esses efeitos de claro e escuro, preto e branco, um jogo daquilo que é visto e do que não é, que acaba por provocar volumes e texturas, interpretações variadas diante de um mesmo objeto. Essa permuta de luz e sombra pode envolver o espectador estimulando-o a associações e sugestões daquilo que é o negro, como tragédia, e daquilo que é claro, como possibilidades. A luz e sombra provocam um caráter intimista e tende a estimular o espectador à reflexão.

Figura 6 - A luz no espetáculo Cão Sem Plumas (2017).

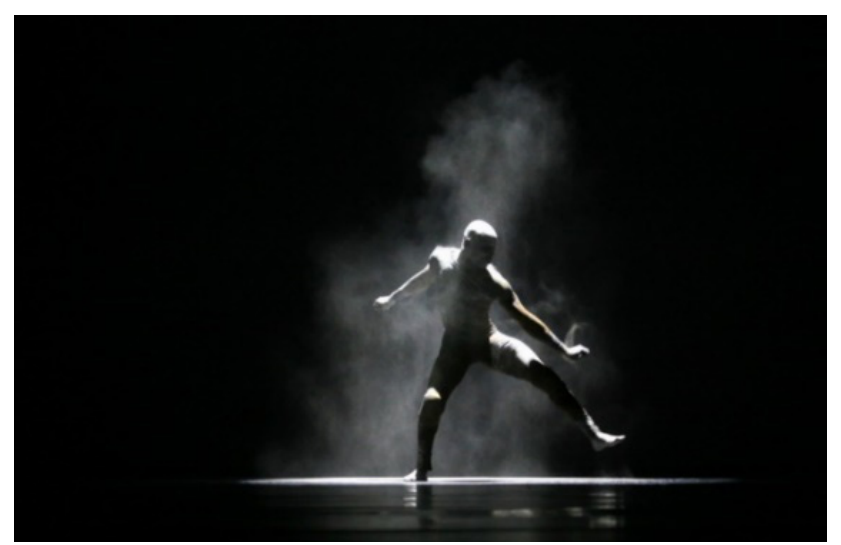

Fonte: Nunes (2017)

A luz também pode intensificar a linguagem da cena, como pode ser observada nas imagens da Figura 7. O azul intensifica uma realidade de possibilidade de vida ou de profundidade, já a luz âmbar ativa o chão, a terra, a força, a resistência, a luta por identidade, territorialidade e dignidade. 
Figura 7 - A luz no espetáculo Cão Sem Plumas (2017)

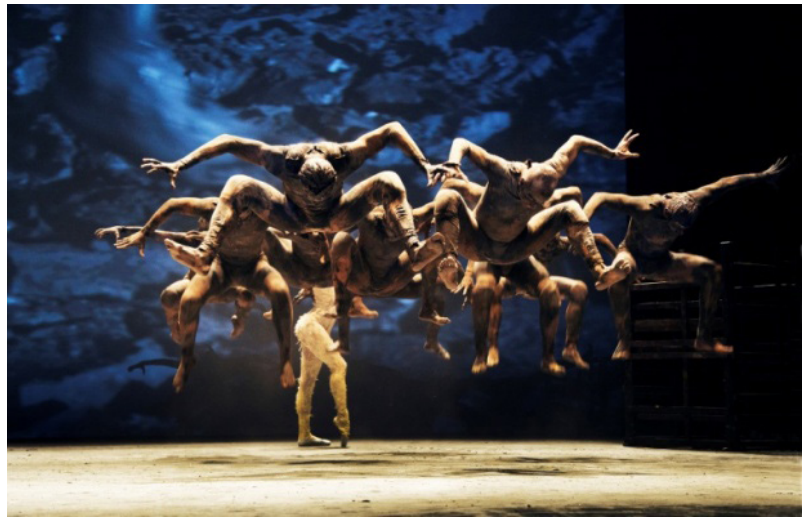

Fonte: Nunes (2017)

Nesse sentido, percebe-se que os aspectos visuais são intensificados pelo telão de fundo. A visão do espectador tende a invadir a imensa imagem de fundo, a qual conecta rapidamente com movimento dos bailarinos que saem da tela imprimindo uma realidade tridimensional, buscando envolver de forma intangível a plateia. Não se sabe quando o bailarino está no palco ou no filme, como visto na Figura 8. Há uma força tanto de imagem, quanto de cena que busca penetrar na mente daquele que as observa.

Figura 8 - Narrativa visual no espetáculo Cão Sem Plumas (2018)

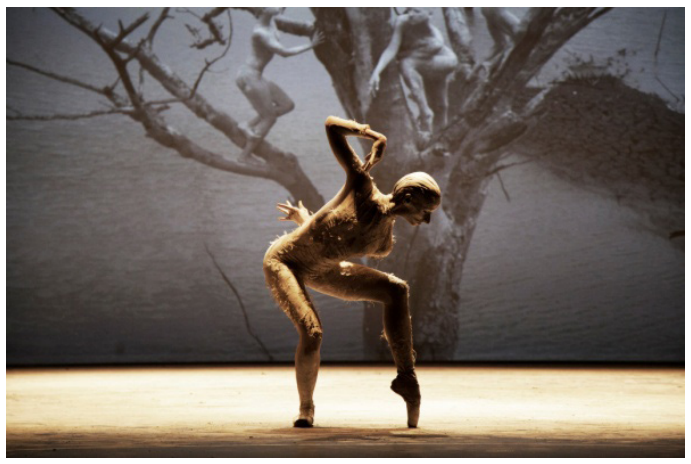

Fonte: (DEBORA ..., 2018). 
Projética, Londrina, v. 12, n. 2, p. 215-239, agosto 2021

Além disso, as imagens também auxiliam na intensidade da mensagem a ser transmitida. Na figura 9, percebe-se a leitura no homem que sofre. A imagem de fundo está em maior dimensão, ampliando a realidade suportada desse homem. “Como o rio aqueles homens são como cães sem plumas (um cão sem plumas é mais que um cão saqueado; é mais que um cão assassinado)", é o que sugere o poema.

Figura 9 - Narrativa visual no espetáculo Cão Sem Plumas (2018)

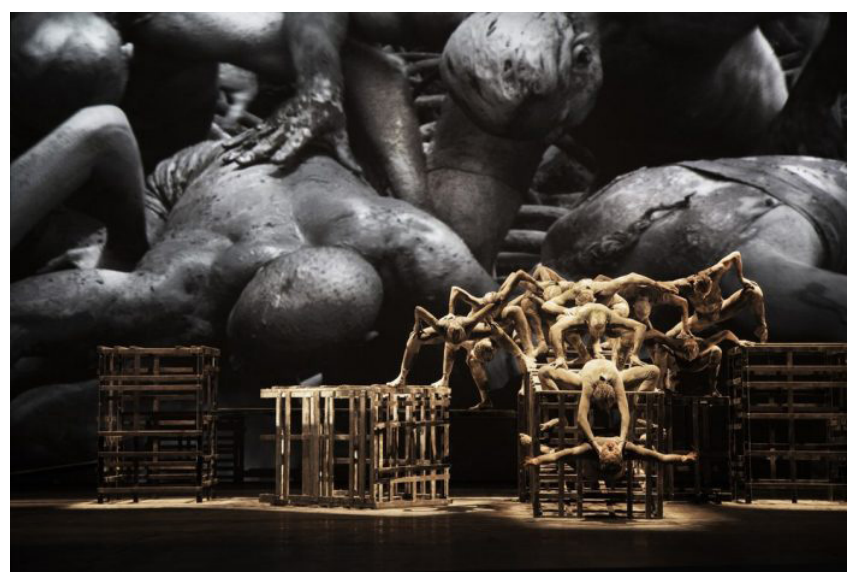

Fonte: (DEBORA ..., 2018).

Por fim, pode-se apreender que os aspectos subjetivos presentes no design de espaços efêmeros são capazes de transmitir uma mensagem, uma ideia ou um conceito. É justamente através da sutileza da mensagem intangível que o espectador pode apreender os valores culturais e as críticas sociais por trás do poema e do espetáculo Cão Sem Plumas. Ressalta-se ainda, como a importância do desenvolvimento de um projeto, mesmo que para um espaço temporário, se torna imprescindível para a transmissão correta da mensagem e para o êxito do processo de comunicação entre o espetáculo e o espectador. 
Aspectos subjetivos no processo... Plumas

CUNHA, A. S. L. da; ABREU, S. M. B. M. de; LANA, S. L. B.

\section{CONSIDERAÇÕES FINAIS}

O efêmero é a melhor representação da sociedade contemporânea, consumista e acelerada. Todavia, a efemeridade também tem seus aspectos positivos, como: a capacidade de síntese, em comunicar uma mensagem em pouco tempo; a intensidade do acontecimento, que cativa e marca uma impressão em quem o experimenta; e a potencialidade de repercutir um assunto, entre outros.

Percebe-se, assim, a potencialidade do efêmero como ferramenta de comunicação nos tempos atuais e que necessita de estratégias eficientes para comunicar com um sujeito tão desejoso de tecnologias e de trocas instantâneas. No contexto do ambiente, o designer é o profissional emissor no processo comunicativo, por isso responsável por projetar maneiras possíveis para melhor transmitir as mensagens até o sujeito e que lhe estimule os sentidos. Logo, o ambiente, a composição de objetos, materiais, entre outros, são arranjos que podem auxiliar nesse diálogo.

Por meio do estudo de caso, foi possível identificar a importância do valor do intangível nessa estrutura comunicativa. A luz, a narrativa visual, o ornamento da cena, o figurino, o som que, aliados a narrativa do poema de Cabral, tornam-se capazes de despertar e envolver o espectador e, também, de levá-lo a ter intensas sensações. Portanto, a análise permitiu perceber como o sujeito pode sentir uma linguagem silenciosa, como essa maneira de comunicar é eficiente e valorosa não só para o efêmero, mas também para outras propostas.

Nesse sentido, acredita-se que o presente trabalho contribuiu para a ampliação do conhecimento sobre os aspectos intangíveis, em especial sobre seu uso no design de espaços efêmeros. Por fim, para estudos futuros, sugere-se tanto o aprofundamento de pesquisas sobre a aplicação dos aspectos subjetivos em outros tipos de ambientes e de seus respectivos processos comunicativos. 
Projética, Londrina, v. 11, n. 2, p.215-239, agosto 2021

REFERÊNCIAS

1. ABREU, Simone Maria Brandão Marques. Aspectos subjetivos relacionados ao Design de Ambientes: um desafio no processo projetual. 2015. 135 f. Dissertação (Mestrado em Design) - Universidade do Estado de Minas Gerais, Belo Horizonte, 2015.

2. BAUMAN, Zigmund. Modernidade líquida. Rio de Janeiro: Jorge Zahar, 2001.

3. BENEVOLO, Leonardo. História da arquitetura moderna. Tradução Ana M. Goldberger. 3. ed. São Paulo: Perspectiva, 2004.

4. BRASIL, Ubiratan. Cão sem plumas é o mais brasileiros do trabalho da coreógrafa Deborah Colker. O Estado de São Paulo, São Paulo, 09 jul. 2017. Disponível em: https://cultura.estadao.com.br/noticias/teatro-e-danca,caosem-plumas-e-o-mais-brasileiro-dos-trabalhos-da-coreografa-deborahcolker,70001881712. Acesso em: 23 nov. 2018.

5. CARNIDE, Sara Joana Ferreira. Arquiteturas expositivas efémeras. Lisboa: Universidade Técnica de Lisboa, 2012.

6. CAVALCANTE, Ś́lvia; NÓBREGA, Lana M. A . Espaço e lugar. In: CAVALCANTE, Sílvia; ELALI, Gleice A. (org.). Temas básicos em psicologia ambiental. Petrópolis: Vozes, 2011. p. 182-190.

7. COHEN, Dominique Raquel. Cenografia para além do teatro. 2007. 120 f. Dissertação (Mestrado em Estética e História da Arte) - Universidade de São Paulo, 2007.

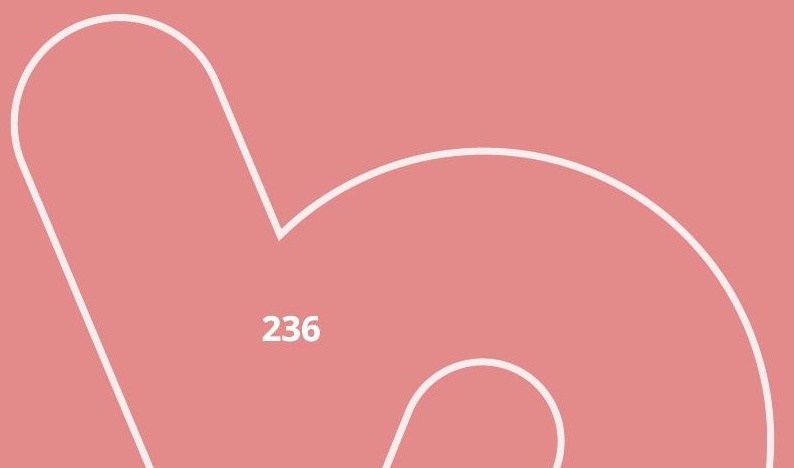


8. DEBORA Colker apresenta "Cão Sem Plumas" neste fim de semana. EsbRASIL, Vitória, 12 mar. 2018. Disponível em: https://esbrasil.com.br/caosem-plumas/. Acesso em: 23 nov. 2018.

9. DESIGN e Semiótica. Vinícius Romanini. [S. l.: s. n.], 2011. 1 vídeo (14min45). Disponível em: http://www.youtube.com/watch?v=OIJzlHeoqf8. Acesso em: 23 nov. 2018.

10. FERNÁNDEZ-GALIANO, L. Espacios Efimeros. Arquitectura Viva, Madrid, n. 141, p. 3, 2011.

11. GONÇALVES, Lisbeth Rebollo. Entre cenografias: o museu e a exposição de arte no século XX. São Paulo: Edusp, 2004.

12. HALL, Edwad T. A dimensão oculta. Tradução de Waldéa Barcellos. São Paulo: Martins Fontes, 2005.

13. LIPOVETSKY, Gilles. A era do vazio: ensaios sobre o individualismo contemporâneo. Barueri: Manole, 2005.

14. MAGALHÃES, Renata. Leia crítica da nova peça de Deborah Colker antes da estreia. Veja Rio, Rio de Janeiro, 10 jun. 2017. Disponível em: https://vejario. abril.com.br/programe-se/leia-critica-da-nova-peca-de-deborah-colkerantes-da-estreia/. Acesso em: 23 nov. 2018.

15. MANTOVANI, A. Cenografia. São Paulo: Ática, 1989.

16. MELIANDE, Clara de Souza Rocha. Design à mostra: o projeto de museus temáticos. 2013. 200 f. Dissertação (Mestrado em Design) - Universidade do Estado do Rio de Janeiro, Rio de Janeiro, 2013.

17. MONTAGU, Ashley. Tocar, o significado humano da pele. São Paulo: Summus, 1988.

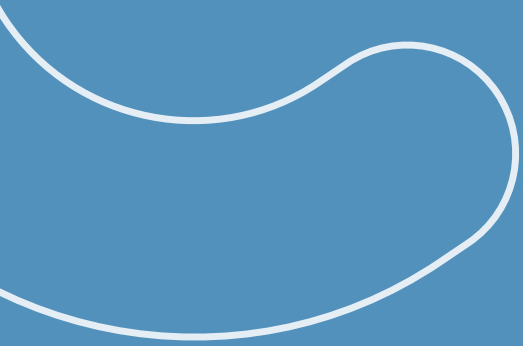


Projética, Londrina, v. 11, n. 2, p.215-239, agosto 2021

18. MONASTERIO, Clélia Maria Coutinho Teixeira. O processo de projeto da arquitetura efêmera vinculada a feiras comerciais. 2006. $248 \mathrm{f}$. Dissertação (Mestrado em Engenharia Civil) - Universidade Estadual de Campinas, Campinas, 2006.

19. NISHIKAWA, Gabriel Queiroz. Uso do espaço efêmero aliado ao design para a experiência em benefício de marcas de moda. 2016. Monografia (Tecnólogo em Design de Moda) - Faculdade de Tecnologia Senai, Curitiba, 2016.

20. NUNES, Lívia. Deborah Colker lota o Teatro Trianon com "Cão sem Plumas". Portal Campos, Campos de Goytacazes, 17 nov. 2017. Disponível em: https://campos.rj.gov.br/exibirNoticia.php?id_noticia=42381. Acesso em: 23 nov. 2018.

21. OKАMOTO, Jun. Percepção ambiental e comportamento: visão holística da percepção ambiental na arquitetura e na comunicação. São Paulo: Editora Mackenzie, 2002.

22. ROMANINI, Vinícius. Design como comunicação: uma abordagem semiótica. In: SEMINÁRIO DO CURSO DE DESIGN DA FAU-USP-DESIGN: QUO VADIS, 1. 2008. São Paulo. Anais [...]. São Paulo: FAUUSP, 2008. p. 1-5.

23. ROMERO, Rafael. Veja imagens da preparação em Pernambuco para o espetáculo "Cão Sem Plumas" da Cia. de Dança Deborah Colker. Blog Social 1. Recife, 12 maio 2017a. Disponível em: https://blogs.ne10.uol.com.br/ social1/2017/05/12/veja-imagens-da-preparacao-em-pernambuco-para-oespetaculo-cao-sem-plumas-da-cia-de-danca-deborah-colker/. Acesso em: 23 nov. 2018. 
Aspectos subjetivos no processo... Plumas

CUNHA, A. S. L. da; ABREU, S. M. B. M. de; LANA, S. L. B.

24. ROMERO, Rafael. "Cão sem Plumas", de Deborah Colker, volta ao Recife. Blog Social 1. Recife, 30 out. 2017b. Disponível em: https://blogs.ne10.uol.com. $\mathrm{br} /$ social1/2017/10/30/cao-sem-plumas-de-deborah-colker-volta-ao-recife/. Acesso em: 23 nov. 2018.

25. VIEGAS, Lucas Corrêa . Cia de dança Deborah Colker apresenta "Cão sem Plumas" em Porto Alegre. No Palco hub Cultural, 29 maio 2017. Disponível em: https://www.jornalnopalco.com.br/2017/05/29/cia-de-danca-deborahcolker-apresenta-cao-sem-plumas-em-porto-alegre/. Acesso em: 23 nov. 2018.
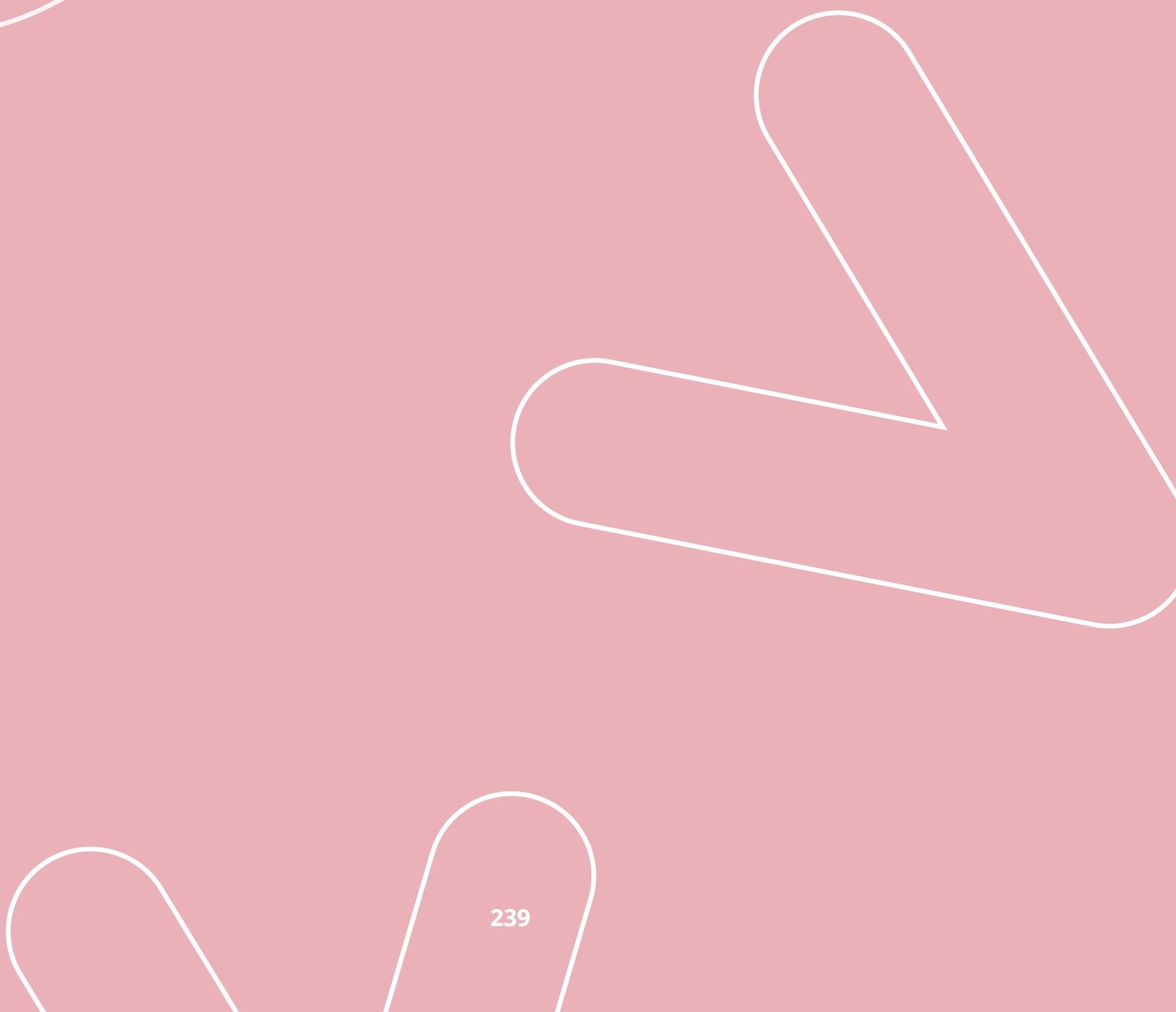